\title{
Humane Papillomviren
}

\section{Weshalb Sie auch Jungen gegen HPV impfen sollten}

\section{PD Dr. Andreas M. Kaufmann, Berlin}

Die HPV-Impfung ist auch bei Jungen sicher und wirksam und hat das Potenzial, eine große Krankheitslast bei beiden Geschlechtern zu verhindern.

Die Prävalenz Humaner Papillomviren (HPV) unterscheidet sich bei Frauen und Männern: Während im Alter von 20-25 Jahren bis zu 50\% aller Frauen HPV-positiv sind und diese Rate zum 35. Lebensjahr hin auf 5-10\% abfällt, sind Männer in allen Altersgruppen zu 40-60\% HPVpositiv und entwickeln nur schwache Immunität. Dies gehört zur Verbreitungsstrategie des Virus, das einen effektiven Vektor zur Übertragung und Überbrückung der Generationen braucht, um möglichst viele Frauen zu infizieren.

\section{Vorteil durch Herdenimmunität}

Während Condylomata bei beiden Geschlechtern vergleichbar häufig auftreten, sind HPV-assoziierte invasive Karzinome bei Männern insgesamt deutlich seltener als bei Frauen, bei denen das
Zervixkarzinom den Hauptteil der Krankheitslast ausmacht. Anders herum verhält es sich jedoch bei Kopf-Hals-Karzinomen oder Analkarzinomen bei Risikopopulationen wie Männern, die Sex mit Männern haben (MSM). Hier vermittelt eine Impfung von Jungen einen direkten Vorteil, wenn man das Individuum betrachtet. Populationsbezogen kommt die Unterstützung einer Herdenimmunität hinzu, die indirekt Ungeimpfte schützt - und bei der Impfung von Jungen wahrscheinlich einen Beitrag zum Schutz vor Gebärmutterhalskrebs bei Frauen leistet.

Mit der erstaunlich hohen Effektivität der HPV-Impfstoffe könnten letztlich die Impfstoff-HPV-Typen vollständig verdrängt werden. Einen Hinweis dazu liefern Daten aus Australien, wo die frühen

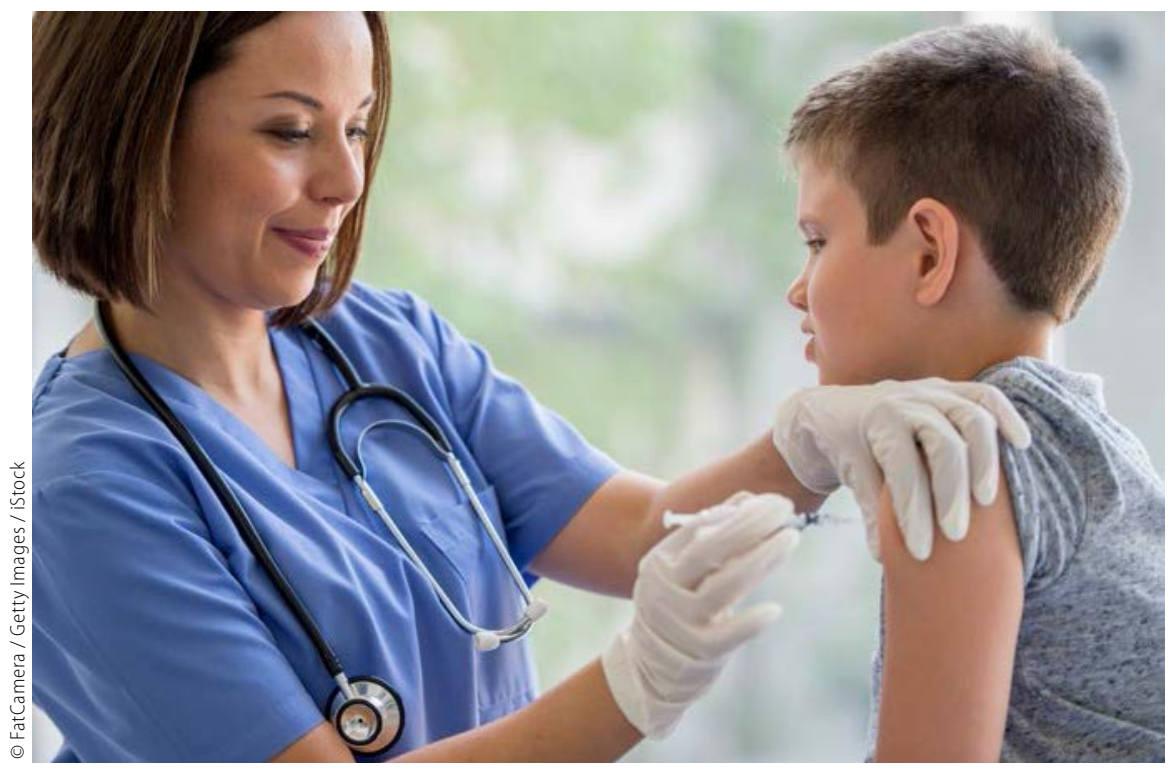

Durch die Impfung ist er gegen HPV geschützt, und später auch seine Partnerin. und erfolgreichen Impfprogramme zu einer schnellen Abnahme an Kondylomen und Dysplasien bei Frauen führten. Signifikante Effekte der Herdenimmunität wurden bei der Abnahme von Kondylomen um über $70 \%$ auch bei ungeimpften jungen Männern beobachtet. Vor diesem Hintergrund erscheint es wichtig, auch Jungen in die Impfempfehlung einzubeziehen.

\section{STIKO-Empfehlungen}

Derzeit besagt die Empfehlung der Ständigen Impfkommission (STIKO) in Deutschland, Mädchen und Frauen im Alter von 9-17 Jahren mit 2 (Alter 9-14 Jahre) bzw. 3 Impfdosen (15-17 Jahre) zu immunisieren. Die drei zugelassenen und verfügbaren Impfstoffe sind auch zur Anwendung bei Jungen und Männern zugelassen.

Randomisierte klinische Studien haben inzwischen die hohe Sicherheit und Effektivität in der Verhinderung von Kondylomen und analen präinvasiven Läsionen bei Männern belegt. Damit ist die evidenzbasierte Datenlage für eine Impfempfehlung geschaffen.

In Deutschland hat die Sächsische Impfkommission (SIKO) bereits 2012 die HPV-Impfung von Jungen empfohlen. Die Kommission der S3-Leitlinie „Impfprävention HPV-assoziierter Neoplasien" (www.hpv-impfleitlinie.de) hat ebenfalls die Impfung von Jungen begründet. Mit Durchimpfungsquoten von nur ca. $50 \%$ über das Altersspektrum von 9-17 Jahren bei Mädchen bleiben weiterhin 50\% der Mädchen und jungen Frauen einem Infektions-Risiko ausgesetzt, da Jungen nicht geimpft und weiterhin Überträger sind.

Während die meiste Krankheitslast, die verhindert werden soll, tatsächlich Frauen betrifft, ist die Infektion, die die Impfung tatsächlich verhindert, bei beiden Geschlechtern gleichermaßen vertreten, was die gleichwertige Impfung von Mädchen und Jungen begründen sollte. 